\title{
A ESCARIFICAÇÃO DO SOLO EM SISTEMA DE PLANTIO DIRETO AFETA A ESTABILIDADE DE AGREGADOS E O TEOR DE MATÉRIA ORGÂNICA EM LATOSSOLO VERMELHO
}

\author{
Paulo Angelo Fachin \\ Universidade Estadual do Centro-Oeste, UNICENTRO. \\ Departamento de Geografia. Laboratório de Erosão dos Solos \\ fachinpa@gmail.com \\ Edivaldo Lopes Thomaz \\ Universidade Estadual do Centro-Oeste, UNICENTRO. \\ Departamento de Geografia. Laboratório de Erosão dos Solos \\ edilopes.thomaz@gmail.com
}

\begin{abstract}
RESUMO
A escarificação do solo em Sistema de Plantio Direto (SPD) é uma alternativa para rompimento de camadas compactadas que impedem o desenvolvimento radicular das plantas, a aeração e a circulação de água no solo no decorrer dos anos de manejo. A escarificação acarreta impactos na qualidade do solo, podendo a longo prazo causar efeitos negativos, como redução do estoque de carbono, e/ou positivos, como aumento da infiltração de água. O objetivo deste estudo foi avaliar o efeito da escarificação na estabilidade dos agregados e nos teores de matéria orgânica do solo em diferentes anos de manejo pós escarificação. Para isto se utilizou de uma área experimental na mesma encosta com latossolo vermelho em diferentes tratamentos: floresta nativa; SPDs (sem escarificação); SPD 1 (1 ano pós escarificação); $\mathrm{SPD}_{3}$ (3 anos pós escarificação) e $\mathrm{SPD}_{4}$ (4 anos pós escarificação). Os resultados mostraram que o índice de estabilidade de agregados aumentou nos anos posteriores a escarificação e os teores de matéria orgânica reduziram, que sugerem efeitos extrínsecos no aumento da estabilidade de agregados.
\end{abstract}

Palavras-chave: Qualidade física. Manejo. Solo.

\section{THE SOIL SCARIFICATION WITH DIRECT PLANTING SYSTEM AFFECTS THE STABILITY OF AGGREGATES AND THE CONTENT OF ORGANIC MATTER IN A RED OXISOL}

\begin{abstract}
Soil scarification in the Straight Planting System (SPD) is an alternative for the rupture of compacted layers that prevent the root development of plants, aeration and water circulation in the soil during the years of management. Scarification entails some effects on the physical behavior of the soil, in the long term cause negative effects like reduction of carbon stock, and / or positive as increased water infiltration. The objective of this study was to evaluate the effect of scarification on the stability of aggregates and soil organic matter contents in different years of post - scarification management. For this, an experimental area was used on the same slope with red oxisol in different treatments: native forest; SPDs (no scarification); $\mathrm{SPD}_{1}$ (1 year post scarification); $\mathrm{SPD}_{3}$ (3 years post scarification) and $\mathrm{SPD}_{4}(4$ years post scarification). The results showed that the aggregate stability index increased in the years after scarification and the organic matter content decreased, showing extrinsic effects on the increase of aggregate stability.
\end{abstract}

Keywords: Physical Quality. Management. Soil.

\section{INTRODUÇÃO}

As mudanças de uso do solo induzidas pelas atividades agrícolas e pecuárias são fatores significativos nas mudanças comportamentais dos parâmetros físicos e químicos do solo. Para bom desenvolvimento radicular das plantas é necessária boa qualidade física dos solos agrícolas (valores ideiais de densidade, porosidade, resistência à penetração, condutividade hidráulica, estabilidade de agregados). Um dos grandes impactos do uso agrícola e pecuário é a compactação do solo, que

$\begin{array}{lllll}\text { Caminhos de Geografia } \quad \text { Uberlândia-MG } & \text { v. 21, n. } 77 & \text { Out/2020 } & \text { p. 18-28 } & \text { Página } 18\end{array}$


limita o desenvolvimento radicular da planta, e resulta na menor capacidade da planta em acessar água e nutrientes do solo em menor produtividade (DEBIASI et al., 2010). Estima-se que aproximadamente 70 milhões de hectares das áreas agrícolas da Terra se encontram em diferentes estágios de degradação, muitas destas, em razão dos efeitos negativos da compactação do solo (ALAKUKKU et al., 2003).

Um dos principais causadores da compactação dos solos em áreas agrícolas com SPD (Sistema de Plantio Direto) é o intenso tráfego de máquinas agrícolas, que resulta na compactação dos solos. Em SPD, onde há ausência do revolvimento do solo, estes efeitos são observados mais facilmente nas camadas superficiais, pois com o tráfego das máquinas e a ausência de revolvimento no decorrer dos anos, facilita a formação da camada compactada, ou camada de impedimento ao desenvolvimento radicular, que contribui para a redução da infiltração de água no solo, aumento no escoamento superficial, formação de ravinas e voçorocas e aumento nas taxas de erosão (HILLEL, 2004; LEPSCH, 2010; MORGAN, 2005; SALES et al., 2016).

Como forma de reduzir estes efeitos da compactação dos solos e as suas limitações físico-hídricas, bem como, seu impedimento na produtividade das culturas, é comum em alguns casos, o uso de escarificador. Este equipamento promove o rompimento das camadas compactadas em profundidades entre 20 e $30 \mathrm{~cm}$, através da ação de hastes, sem o tombamento da leiva, ocorrendo um menor revolvimento superficial do solo, além da manutenção da maior parte da palhada na superfície (CORTEZ et al., 2011).

Deste modo, a escarificação permite descompactar a camada superficial, reduzir a densidade do solo e a resistência à penetração de raízes, aumentar a permeabilidade, reduzir o encharcamento em terrenos planos com o aumento da rugosidade da superfície e da qualidade produtiva do solo (LEPSCH, 2010).

No entanto, com a escarificação alguns parâmetros relacionados à estrutura dos agregados podem ser alterados, dentre eles o teor de matéria orgânica, diâmetro médio e estabilidade dos agregados, pois durante a escarificação os agregados têm sua estrutura quebrada sendo reduzidos de tamanho podendo afetar a capacidade de resistirem aos processos erosivos (REYS et al., 2014) . Do mesmo modo, a matéria orgânica pode ser alterada, afetando diretamente a resiliência do solo e dos agregados. Vale ressaltar que o tipo da escarificação (modelo do escarificador, profundidade da escarificação, número de repetições, condições de umidade do solo, velocidade de passada, e a estação climática das operações de preparo) afeta de forma diferente o comportamento dos agregados e da matéria orgânica posteriormente.

A formação de agregados está condicionada a vários fatores, como o tipo e o teor de argila, silte e areia; mineralização, óxidos e os hidróxidos que são agentes de ligação das partículas, substâncias e exudatos orgânicos oriundos das plantas e da ação microbiana, teor de matéria orgânica, carbono orgânico, e outros (BLANKINSHIP et al., 2016; SEIDEL et al., 2018; SARKER et al., 2018). No entanto, os principais elementos condicionantes da agregação são os de caráter orgânico.

A escarificação pode ter efeitos diretos e indiretos a curto e em longo prazo nos fatores de formação dos agregados, pois esta prática expõe parte do solo subsuperficial na superfície em ambiente com diferentes níveis e ciclos de umedecimento e secagem, congelamento e degelo dependendo da região climática, diferentes gradientes de temperatura, altera a taxas de decomposição da matéria orgânica, afeta a comunidade microbiana (PAUSTIAN et al., 1997; CAMBARDELLA e ELLIOTT, 1993).

Para manutenção da estabilidade dos agregados pós escarificação, é recomendado a adoção medidas conservacionistas, como o SPD (Sistema de Plantio Direto) a fim de promover o crescimento de fungos e a proliferação de hifas fúngicas que contribuem para a formação de macroagregados (BEARE et al., 1994), a rotação de culturas de características radicular variadas, cobertura morta de colheitas na superfície para que haja diversidade na incrementação do teor de matéria orgânica, proporcionando estabilização dos agregados do solo e formação de novos agregados estáveis (KOCHHANN et al., 2000; CALONEGO e ROSLEM, 2008).

Baseado na necessidade de maior compreensão sobre os efeitos desta prática no solo, o presente trabalho teve como objetivo avaliar a influência da escarificação na estabilidade dos agregados, diâmetro médio dos agregados e teor de matéria orgânica do solo em SPD com diferentes anos de manejo após a escarificação. 


\section{DESENVOLVIMENTO E METODOLOGIA}

\section{Local de estudo}

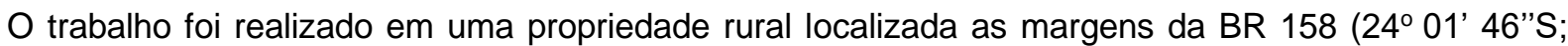
$52^{\circ}$ 19'01"O) no município de Campo Mourão-PR (Figura 1). O clima da região é classificado como subtropical úmido mesotérmico, com verões quentes e geadas pouco frequentes, com tendência de concentração das chuvas nos meses de verão, sem estação seca definida, de acordo com a classificação de Köppen-Geiger.

Figura 1 - Localização da área de estudo.

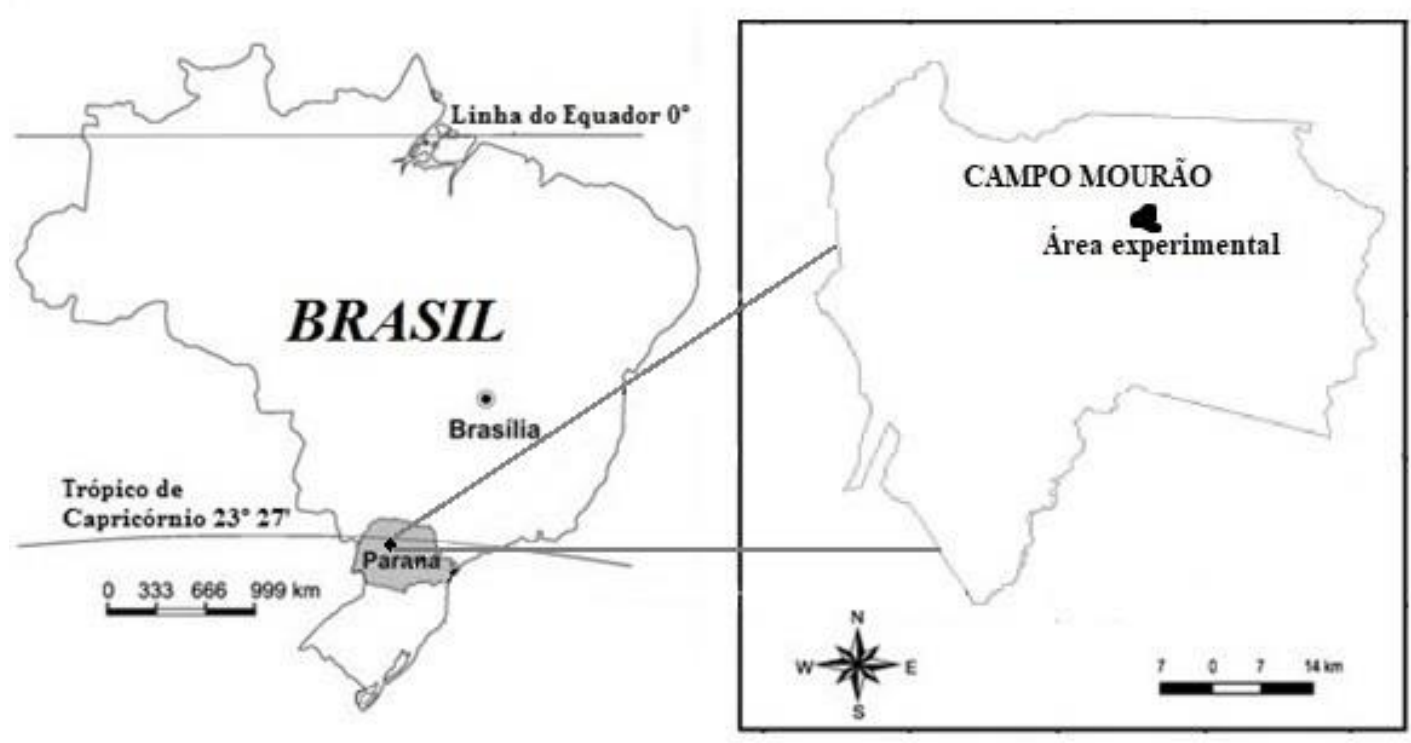

Fonte - (FACHIN et al,. 2019).

A área está submetida a sistema de plantio direto há aproximadamente 30 anos, com semeadura de soja e milho no verão e aveia ou trigo no inverno. O solo do local é classificado como Latossolo Vermelho Distroférrico de textura muito argilosa (EMBRAPA, 2013), areia $14 \%$, silte $23 \%$, argila $63 \%$. Para a escarificação das áreas o agricultor utilizou o escarificador $\mathrm{Fox}^{\circledR}$ que possui nove hastes em formato parabólico com $3 \mathrm{~cm}$ de espessura, espaçadas $30 \mathrm{~cm}$ entre si, com profundidade de operação de $25 \mathrm{~cm}$ e velocidade de trabalho de $5 \mathrm{~km} / \mathrm{h}$.

As parcelas estão todas localizadas na mesma encosta com declividade baixa de aproximadamente $7 \%$. O delineamento adotado foi inteiramente casualizado com cinco tratamentos: Floresta nativa; Sistema de Plantio Direto sem escarificação (SPDs); um ano pós escarificar (SPD 1 ); três anos pós escarificar $\left(\mathrm{SPD}_{3}\right)$ e quatro anos pós escarificar $\left(\mathrm{SPD}_{4}\right)$. O solo foi coletado na camada de $0-20 \mathrm{~cm}$ da superfície em formato de blocos indeformados de modo a não desestruturar os agregados, posteriormente as amostras foram levadas para análises em laboratório.

\section{Delineamento experimental e avaliações}

Os solos foram secos a temperatura ambiente em laboratório $\left(21^{\circ} \mathrm{C}\right)$ por 4 dias e em seguida foram separados para amostragem.

Para cada tratamento (Floresta; SPDs; $\mathrm{SPD}_{1} ; \mathrm{SPD}_{3}$ e $\mathrm{SPD}_{4}$ ) foram separadas 6 amostras de $25 \mathrm{~g}$ peneiradas em peneira de malha de $8 \mathrm{~mm}$ por 5 minutos para cada análise física: índice de estabilidade de agregados (IEA); diâmetro médio ponderado (DMP), peneiramento seco (PS), e 3 repetições de cada tratamento para análise de matéria orgânica (MO). 
Para determinação no peneiramento seco (PS), cada uma das 6 amostras de $25 \mathrm{~g}$ foram peneiradas por 30 segundos em agitador de peneira eletromecânico para separar as classes de agregados. As amostras foram fracionadas de acordo com as seguintes classes granulométricas: $4,0 \mathrm{~mm} ; 2,0 \mathrm{~mm}$; $1,0 \mathrm{~mm} ; 0,5 \mathrm{~mm} ; 0,250 \mathrm{~mm}, 0,125 \mathrm{~mm} ;<0,125 \mathrm{~mm}$. Em seguida, pesou-se a fração retida em cada peneira e estabeleceu-se a porcentagem de cada classe utilizando a equação 1 .

$$
A \%=\frac{P A R}{P A T} \times 100
$$

Equação 1

$\mathrm{A} \%=$ Agregado retido na peneira em porcentagem

$\mathrm{PAR}=$ Peso de agregado retido na peneira $(\mathrm{g})$

$\mathrm{PAT}=$ Peso total da amostra total $(\mathrm{g})$

Para estimativa da estabilidade de agregados via úmida foi realizado o peneiramento submerso em água (PU). Para tanto foram usados $25 \mathrm{~g}$ de solo de cada amostra, que foram pré-umedecidos por 10 minutos, conforme o princípio de umedecimento lento descrito por Kemper \& Chepil (1965). Em seguida, o material foi agitado levemente em agitador de Yoder com agitação vertical por 10 minutos (30 rpm) nas seguintes classes granulométricas: $4,0 \mathrm{~mm} ; 2,0 \mathrm{~mm} ; 1,0 \mathrm{~mm} ; 0,5 \mathrm{~mm} ; 0,250 \mathrm{~mm}, 0,125$ $\mathrm{mm} ;<0,125 \mathrm{~mm}$. O procedimento empregado no peneiramento submerso foi adaptado a partir de Yoder (1936).

O material retirado de cada peneira foi transferido para becker de vidro e seco a $105^{\circ} \mathrm{C}$ por 24 horas em estufa de aquecimento, em seguida foi pesada a fração retida em cada peneira.

Em ambos os procedimentos a distribuição e quantidade de agregados (peso-volume) de uma peneira para outra foi obtida por meio da razão entre a quantidade de agregados retidos em cada peneira pelo total de material avaliado. Os índices dos agregados: diâmetro médio ponderado, e estabilidade de agregado sem porcentagem, foram obtidos por meio das equações abaixo:

$$
D M P=\sum x_{i} y_{i} \quad \text { Equação } 2
$$

DMP = Diâmetro Médio Ponderado

$x=$ Diâmetro médio da classe de agregados $(\mathrm{mm})$

$i y=$ Proporção de agregado retido em cada classe em relação

à amostra total

$$
E A \%=\frac{P A R-P A<0,25 \mathrm{~mm}}{P T A} \times 100
$$

\section{Equação 3}

IEA\%= Estabilidade de Agregados em porcentagem

PAR $=$ Peso de Agregados Retidos $>0,25 \mathrm{~mm}$

$\mathrm{PA}=$ Peso de Agregados $<0,25 \mathrm{~mm}$

PTA $=$ Peso Total da Amostra

O DMP aumenta à medida que os agregados maiores são os que mais ficam retido nas peneiras, e o IEA\% pode variar de 1 a $100 \%$ e indica a agregação de acordo com o manejo do solo (KEMPER \& ROSENAU, 1986; CASTRO FILHO et al., 2002; DÍAZ-ZORITA et al., 2002).

O conteúdo de matéria orgânica do solo (MO) foi determinado pelo método Walkley-Black (1934) em triplicatas para cada tratamento avaliado ( 3 réplicas $\times 5$ tratamentos $=15$ amostras no total). $A$ análise dos dados foi realizada da seguinte forma: 1) estatística descritiva (média, desvio padrão e coeficiente de variação); 2) análise de variância (ANOVA); 3) comparação de médias pelo teste t. A aplicação das técnicas e análises estatísticas seguiu as recomendações e procedimentos contidos em Vieira (1999). 


\section{RESULTADOS E DISCUSSÃO}

Os valores do teor de matéria orgânica (MO), apesar de não significativos no teste t, (figura 2) se apresentaram maior na floresta nativa e decresceram nas demais áreas nos anos seguintes pós escarificação. Este comportamento pode estar atribuído à ação do escarificador, em que parte dos resíduos culturais são incorporados em profundidade, além da maior aeração do solo e consequente destruição dos agregados e exposição das frações de matéria orgânica protegida pelos agregados, proporcionando uma maior ação dos microorganismos que promovem a sua decomposição e consequentemente redução dos teores de MO do solo (COSTA et al., 2008).

Figura 2 - Teor de matéria orgânica de solos em Sistema de Plantio Direto com diferentes tempos de manejo pós escarificação.

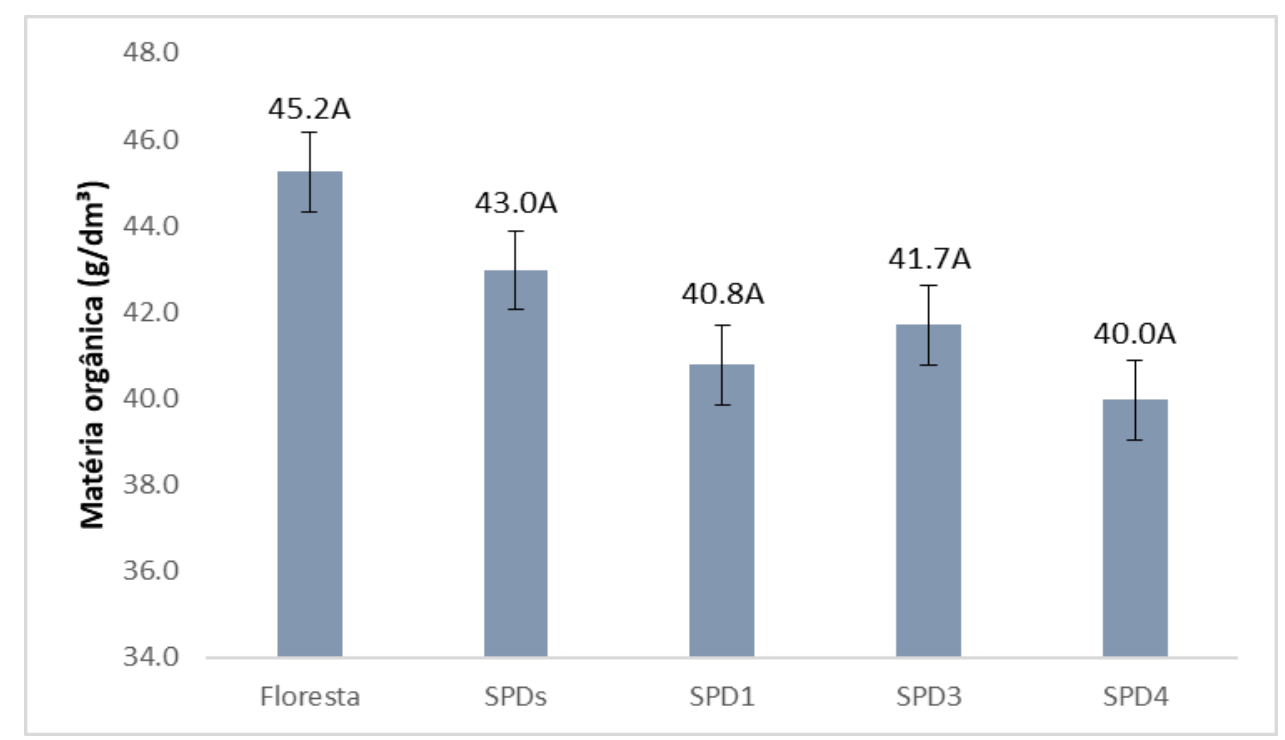

As barras de erro indicam desvio padrão. Letras diferentes indicam diferença significativa a 5\% no teste t.

Alguns estudos têm demonstrado que quando ocorre a retirada da floresta e a substituição por culturas agrícolas, a adição de matéria orgânica no solo é menor, com isso ao longo do tempo a quantidade tende a diminuir, conforme verificado por Moreira e Malavolta (2004) que ao estudarem a dinâmica da matéria orgânica no bioma Amazônia verificaram que há redução nos teores quando a floresta é substituída por pastagem para posterior implantação de agricultura.

A escarificação, apesar de não revolver intensamente o solo, faz com que a matéria orgânica que está protegida dos microrganismos envolta pelos agregados do solo, seja exposta devido a ação das hastes que causam vibrações no solo e também pela ação do rolinho destorroador que quebra os torrões de solo com o objetivo de reduzir a rugosidade.

Isso explica a redução na quantidade de matéria orgânica quando se compara o solo não escarificado e o solo escarificado. Os resultados aqui apresentados mostram que a redução ocorre no primeiro ano pós a escarificação e que depois os teores estabilizam.

Resultados similares foram encontrados por Dadalto et al., (2015) que ao compararem diferentes sistemas de manejo verificaram que o sistema de plantio direto apresentou $39 \%$ a mais de carbono orgânico total que o sistema de cultivo mínimo pós escarificação. Deste modo, a escarificação deixa a matéria orgânica do solo mais exposta potencializando sua redução nos anos seguintes pela ação do manejo e dos agentes naturais, e também dificultando sua incrementação no solo por conta da compactação do topo nos anos posteriores pelo tráfego de maquinários.

O teor de matéria orgânica é fator condicionante de inúmeras variáveis físico-químicas do solo, e sabe-se que os ciclos de umedecimento e secagem influenciam na perda de nutrientes, no estoque de carbono, na dinâmica dos microorganismos e no comportamento da mineralização da matéria orgânica (SIX et al., 1999). Ou seja, num mesmo ambiente com o mesmo tipo de manejo adotado em 
diferentes épocas, a sazonalidade e os níveis de variações de umidade e temperatura durante $o$ ano são fatores consideráveis na agregação do solo e na estabilidade dos agregados.

Segundo a literatura, na maioria dos casos a estabilidade dos agregados tende a diminuir quando o solo é escarificado ou quando os teores de matéria orgânica diminuem (CALONEGO e ROSOLEM, 2008; CASTRO FILHO et al, 2002). No entanto, os resultados em nosso estudo indicaram um padrão diferente, uma vez que se encontrou aumento significativo na estabilidade dos agregados pós a escarificação (figura 3). Isso mostra que a escarificação acompanhada posteriormente de SPD exerce efeito positivo na estabilidade dos agregados, deixando claro que em um ano os agregados revolvidos pela escarificação passam a se tornar mais resistentes as forças disruptivas.

A estabilidade dos agregados foi menor no solo sem escarificação quando comparado ao solo escarificado, isso pode indicar que as áreas estavam com solo compactado antes da escarificação, pois a compactação reduz a estabilidade dos agregados, conforme verificado por Beutler et al. (2005) que constataram redução na estabilidade dos agregados do solo a medida com que aumentou a compactação do solo.

Figura 3 - Índice de Estabilidade de Agregados de solos em Sistema de Plantio Direto com diferentes tempos de manejo pós escarificação.

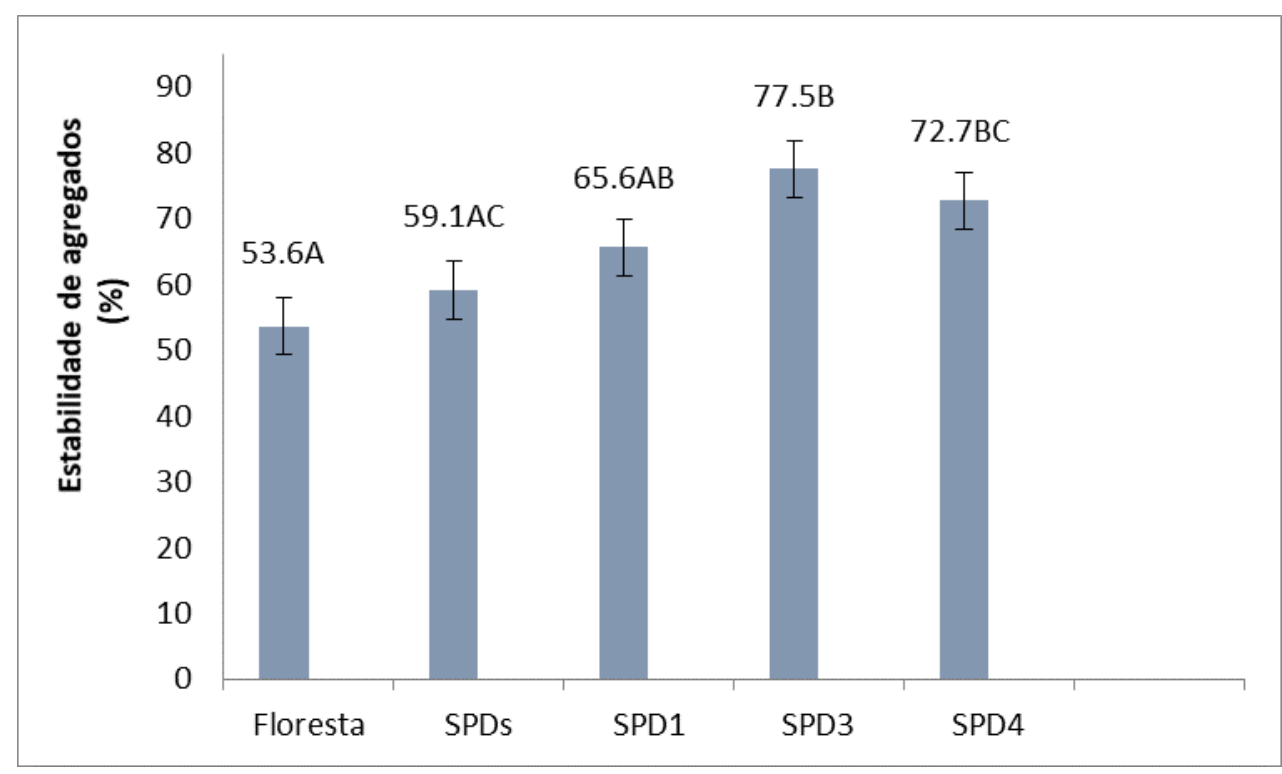

As barras de erro indicam desvio padrão. Letras diferentes indicam diferença significativa a $5 \%$ no teste t.

Isso ocorre porque quando há problemas de compactação o crescimento e a distribuição das raízes no solo é menor, com isso há menos liberação de exsudatos radiculares que agrupa as partículas do solo e compromete a formação de agregados maiores além da redução da ação física das raízes na aproximação as partículas de solo.

Salton et al. (2008), observaram que elevados teores de argila afetam positivamente a estabilidade dos agregados do solo, e no estudo em questão, o solo é muito argiloso (63\%), o que pode ter contribuído para o aumento da estabilidade pós escarificação, pois os teores de matéria orgânica do solo não apresentaram mudança significativa entre as áreas pós a escarificação, e a estabilidade dos agregados aumentou.

De acordo com Bronick \& Lal (2005), em solos tropicais os teores de óxido de Fe e Al associados à argila caulinita desempenham papel importante como agentes cimentantes, uma vez o solo escarificado pode ocorrer a transformação de compostos minerais (isto é, Ferro e oxi-hidróxidos de alumínio), causando a dispersão destes minerais argilosos pela quebra dos agregados e posteriormente a agregação em conjunto com a ação das raízes e da matéria orgânica nos anos seguintes de manejo. No entanto, outros parâmetros físicos devem ser verificados a fim de identificar as causas que mais contribuíram para o aumento da estabilidade de agregados neste estudo. 
Os resultados do diâmetro médio ponderado, em função dos diferentes tempos de manejo de SPD pós escarificação, são apresentados na figura 4. De acordo com a literatura, quanto maior for a porcentagem de agregados grandes, ou seja, retidos nas peneiras com malhas maiores, maior será o DMP.

Comparando-se os diferentes anos de manejo pós escarificação, verifica-se que o DMP variou de $1,65 \mathrm{~mm}$ ( 1 ano pós escarificar) a 2,05 mm (3 anos pós escarificar), observa-se que ocorreu pequena redução no diâmetro médio ponderado dos agregados e aumento no terceiro ano pós escarificação. No entanto as demais áreas não diferem significativamente da floresta, sendo a área 3 anos pós escarificação a que apresentou o maior DMP, coincidindo com o comportamento dos resultados da estabilidade de agregados maior na mesma área.

Figura 4 - Diâmetro Médio Ponderado de agregados de solos em Sistema de Plantio Direto com diferentes tempos de manejo pós escarificação.

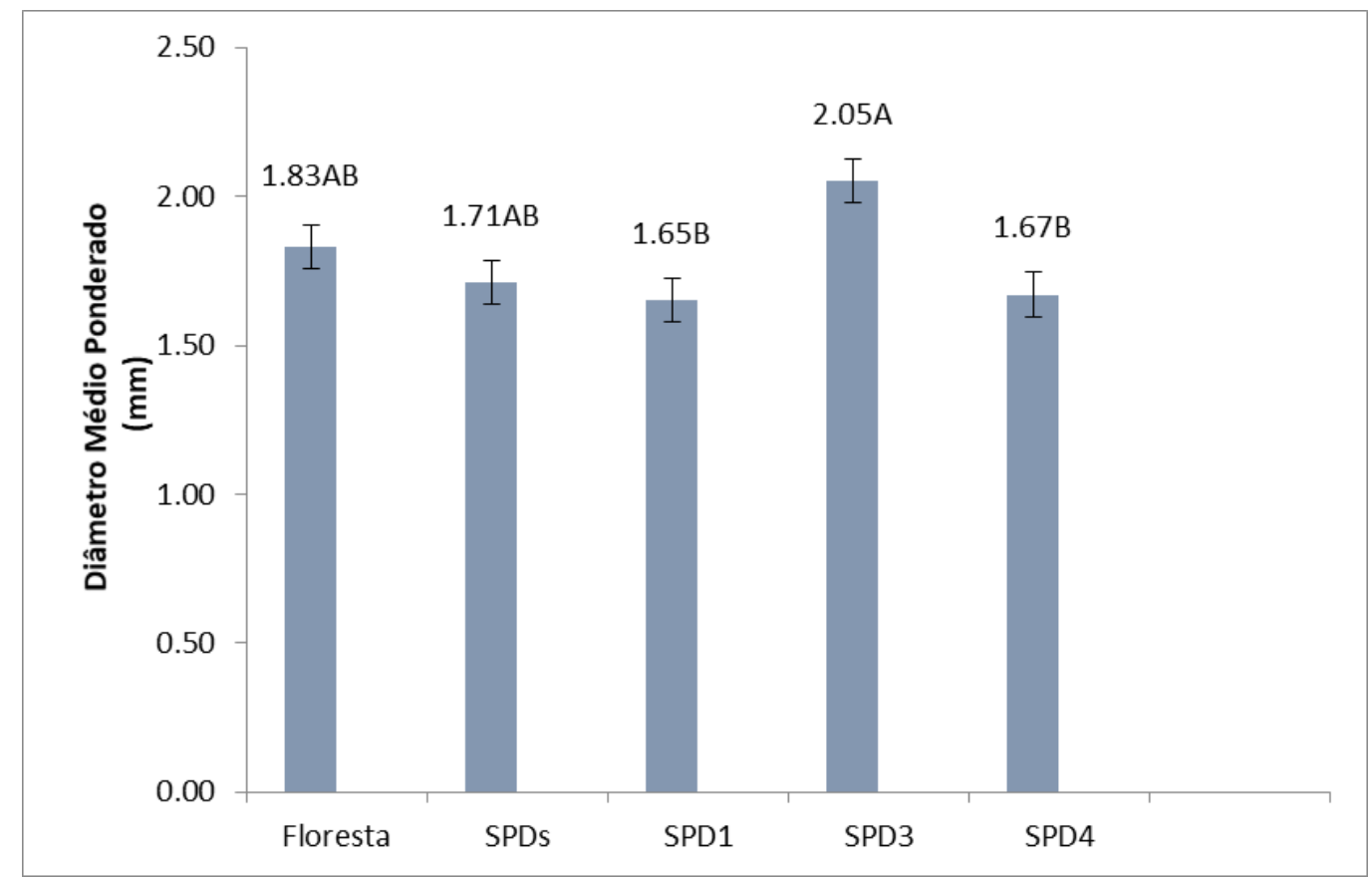

As barras de erro indicam desvio padrão. Letras diferentes indicam diferença significativa a 5\% no teste t.

Os padrões de comportamento da estabilidade de agregados e do diâmetro médio ponderado aqui observados, podem estar diretamente relacionados ao manejo do solo pós escarificação. As áreas com maior tempo de manejo pós escarificação em SPD ao serem cultivadas todos os anos, automaticamente foram submetidas a maior tráfego de maquinários na superfície que as áreas com menor tempo de manejo pós escarificação, e este fator somado a característica argilosa do solo podem inferir no maior adensamento das partículas. Solos argilosos são mais coesos e quando sofrem maior compressão tende a formar agregados maiores e mais adensados, fato este que pode contribuir para maior resistência dos agregados quando submetidos a água elevando a estabilidade dos agregados e o diâmetro médio ponderado.

Os resultados obtidos no peneiramento a seco demonstram a dinâmica do uso do escarificador na quebra da estrutura do solo, sendo que no primeiro ano pós a escarificação, pode-se observar uma redução nas quantidades de macroagregados $(>0,250 \mathrm{~mm})$ presentes. Após 3 e 4 anos ocorre a reestruturação dos solos, sendo que os solos apresentam quantidades de macroagregados semelhantes e até mesmo superiores às observadas em solos nunca escarificados. $\mathrm{O}$ aumento na presença de macroagregados após 3 e 4 anos da escarificação também está relacionado às forças de compressão causadas pelo maior número de passadas de maquinários e implementos nestas duas áreas, que resultou na compactação e compressão dos agregados, tornando-os mais enrijecidos que nas demais áreas (RIBON et al., 2014). 
Tabela 1 - Porcentagem de agregados para os diferentes tratamentos submetidos a peneiramento seco.

\begin{tabular}{lccccc}
\hline $\begin{array}{l}\text { Classe de } \\
\text { agregados }\end{array}$ & Floresta nativa & $\begin{array}{l}\text { Sem } \\
\text { escarificar }\end{array}$ & $\begin{array}{l}\text { 1 ano pós } \\
\text { escarificar }\end{array}$ & $\begin{array}{l}\text { 3 anos pós } \\
\text { escarificar }\end{array}$ & $\begin{array}{l}\text { 4 anos pós } \\
\text { escarificar }\end{array}$ \\
\hline $4,0 \mathrm{~mm}$ & $13,9 \pm 0,5 \mathrm{ac}$ & $25,5 \pm 1,1 \mathrm{abc}$ & $16,1 \pm 0,7 \mathrm{ab}$ & $23,0 \pm 1,5 \mathrm{bc}$ & $29,9 \pm 1,3 \mathrm{abc}$ \\
$2,0 \mathrm{~mm}$ & $20,9 \pm 0,7 \mathrm{a}$ & $20,2 \pm 0,7 \mathrm{a}$ & $24,9 \pm 1,0 \mathrm{a}$ & $27,8 \pm 0,6 \mathrm{a}$ & $27,9 \pm 0,9 \mathrm{a}$ \\
$1,0 \mathrm{~mm}$ & $14,3 \pm 0,4 \mathrm{ac}$ & $13,7 \pm 0,4 \mathrm{abc}$ & $18,7 \pm 0,4 \mathrm{ab}$ & $17,2 \pm 0,3 \mathrm{bc}$ & $16,0 \pm 0,4 \mathrm{abc}$ \\
$0,5 \mathrm{~mm}$ & $14,6 \pm 0,2 \mathrm{ab}$ & $10,4 \pm 0,2 \mathrm{a}$ & $12,8 \pm 0,3 \mathrm{~b}$ & $10,7 \pm 0,5 \mathrm{ab}$ & $9,5 \pm 0,3 \mathrm{ab}$ \\
$0,250 \mathrm{~mm}$ & $20,5 \pm 0,3 \mathrm{a}$ & $14,5 \pm 0,4 \mathrm{a}$ & $14,5 \pm 0,7 \mathrm{a}$ & $11,3 \pm 0,7 \mathrm{a}$ & $9,2 \pm 0,4 \mathrm{a}$ \\
$0,125 \mathrm{~mm}$ & $7,5 \pm 0,3 \mathrm{a}$ & $9,0 \pm 1,1 \mathrm{ab}$ & $6,4 \pm 0,5 \mathrm{ab}$ & $5,1 \pm 0,3 \mathrm{ab}$ & $3,9 \pm 0,2 \mathrm{~b}$ \\
$<0,125 \mathrm{~mm}$ & $8,3 \pm 0,5 \mathrm{a}$ & $6,6 \pm 0,8 \mathrm{a}$ & $6,5 \pm 0,3 \mathrm{ab}$ & $4,9 \pm 0,2 \mathrm{ab}$ & $3,7 \pm 0,3 \mathrm{~b}$ \\
\hline
\end{tabular}

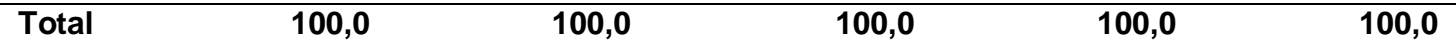

Média \pm desvio padrão. Letras iguais na mesma coluna não diferem significativamente a $5 \%$ no teste t.

De forma geral, vale destacar que em todas as áreas de SPD pós 1 ano de escarificação ocorreu a formação de agregados maiores e redução de agregados menores com igualdade nos agregados intermediários, corroborando os resultados de aumento da estabilidade de agregados nas áreas de SPD pós 1 anos de escarificação.

No peneiramento a úmido observa-se predomínio dos macroagregados $(>0,250)$ com relação ao microagregados $(<0,250)$. Entre as áreas, a floresta e sem escarificação apresentaram valores menores para o macroagregados enquanto as mesmas apresentaram valores maiores para os microagregados.

Tabela 2 - Porcentagem de agregados de para os diferentes tratamentos submetidos a peneiramento submerso em água.

\begin{tabular}{lccccc}
\hline $\begin{array}{l}\text { Classe de } \\
\text { agregados }\end{array}$ & $\begin{array}{l}\text { Floresta } \\
\text { nativa }\end{array}$ & $\begin{array}{l}\text { Sem } \\
\text { escarificar }\end{array}$ & $\begin{array}{l}\text { 1 ano pós } \\
\text { escarificar }\end{array}$ & $\begin{array}{l}\text { 3 anos pós } \\
\text { escarificar }\end{array}$ & $\begin{array}{l}\mathbf{4} \text { anos pós } \\
\text { escarificar }\end{array}$ \\
\hline $4,0 \mathrm{~mm}$ & $15,8 \pm 0,6 \mathrm{ac}$ & $14,4 \pm 1,2 \mathrm{abc}$ & $10,2 \pm 0,7 \mathrm{bc}$ & $16,8 \pm 0,9 \mathrm{abc}$ & $11,6 \pm 0,4 \mathrm{ab}$ \\
$2,0 \mathrm{~mm}$ & $16,9 \pm 0,5 \mathrm{ab}$ & $14,2 \pm 0,5 \mathrm{ab}$ & $19,1 \pm 0,5 \mathrm{a}$ & $19,0 \pm 0,9 \mathrm{ab}$ & $\begin{array}{l}16,0 \pm 0,2 \mathrm{~b} \\
1,0 \mathrm{~mm}\end{array}$ \\
$13,0 \pm 0,2 \mathrm{a}$ & $14,0 \pm 0,2 \mathrm{a}$ & $17,2 \pm 0,5 \mathrm{a}$ & $18,1 \pm 0,5 \mathrm{a}$ & $16,8 \pm 0,2 \mathrm{a}$ \\
$0,5 \mathrm{~mm}$ & $16,9 \pm 0,4 \mathrm{a}$ & $17,2 \pm 0,3 \mathrm{a}$ & $18,1 \pm 0,2 \mathrm{a}$ & $18,7 \pm 0,3 \mathrm{a}$ & $22,5 \pm 0,8 \mathrm{a}$ \\
$0,250 \mathrm{~mm}$ & $11,5 \pm 0,9 \mathrm{a}$ & $15,1 \pm 1,0 \mathrm{a}$ & $14,3 \pm 0,6 \mathrm{a}$ & $12,5 \pm 0,4 \mathrm{a}$ & $14,2 \pm 1,1 \mathrm{a}$ \\
$0,125 \mathrm{~mm}$ & $5,4 \pm 0,7 \mathrm{a}$ & $9,4 \pm 0,7 \mathrm{a}$ & $7,7 \pm 0,7 \mathrm{a}$ & $7,7 \pm 0,6 \mathrm{a}$ & $10,5 \pm 1,1 \mathrm{a}$ \\
$<0,125 \mathrm{~mm}$ & $20,5 \pm 0,4 \mathrm{a}$ & $15,7 \pm 0,4 \mathrm{a}$ & $13,4 \pm 0,2 \mathrm{a}$ & $7,2 \pm 0,8 \mathrm{a}$ & $8,4 \pm 0,5 \mathrm{a}$ \\
\hline Total & $\mathbf{1 0 0 , 0}$ & $\mathbf{1 0 0 , 0}$ & $\mathbf{1 0 0 , 0}$ & $\mathbf{1 0 0 , 0}$ & $\mathbf{1 0 0 , 0}$ \\
\hline
\end{tabular}

Média \pm desvio padrão. Letras iguais na mesma coluna não diferem significativamente a 5\% no teste t.

O peneiramento úmido comprovou que as classes de agregados nas áreas escarificadas apresentam maior resistência a desagregação que a floresta e a sem escarificar, comprovando o aumento da estabilidade de agregados e sua maior resistência a desagregação, pois quanto maior a presença de agregados maiores significa maior resistência do material a desagregação e água.

\section{CONCLUSÕES}

1. A escala temporal avaliada neste estudo em SPD pós escarificação não apresentou diferença significativa nos teores de $\mathrm{MO}$;

2. Os peneiramentos secos e úmidos comprovaram o aumento do tamanho e da resistência dos macroagregados três anos pós escarificação em SPD;

$\begin{array}{llllll}\text { Caminhos de Geografia } & \text { Uberlândia-MG } & \text { v. 21, n. } 77 & \text { Out/2020 } & \text { p. 18-28 } & \text { Página } 25\end{array}$


3. Os resultados mostraram aumento da estabilidade de agregados mesmo não ocorrendo diferença nos teores de $\mathrm{MO}$, trazendo a necessidade de novos estudos que busquem investigar de forma mais refinada os mecanismos que condicionaram o aumento da estabilidade de agregados, além de outros atributos físicos do solo em SPD nos anos seguintes pós escarificação.

\section{AGRADECIMENTOS}

O primeiro autor agradece a Coordenação de Aperfeiçoamento de Pessoal de Nível Superior CAPES pela concessão de bolsa de doutorado. O segundo autor agradece ao Conselho Nacional de Desenvolvimento Científico e Tecnológico - CNPq, pela concessão de Bolsa Produtividade.

\section{REFERÊNCIAS}

ALAKUKKU, L.; WEISSKOPF, P.; CHAMEN, W. C. T.; TIJINK, F. G. J.; LINDEN, J. P. VAN DER; PIRES, S.; SOMMER, C.; SPOOR, G. Prevention strategies for field traffic-induced subsoil compaction: a review: part I: machine/soil interactions. Soil and Tillage Research, v. 73, n. 1/2, p. 145-160, 2003.

BEARE M. H.; HENDRIX P. F.; COLEMAN D. C. Water-stable aggregates and organic matter fraction in conventional and no-tillage soils. Soil Science Society of America Journal v. 58, p. 171-786. 1994. https://doi.org/10.2136/sssaj1994.03615995005800030020x

BEUTLER, A. N.; CENTURION, J. F.; FREDDI, O. da S.; ANDRIOLI, I. Efeito da compactação do solo na estabilidade de agregados e no conteúdo gravimétrico de água. Acta Scientiarum Agronomy, v. 27, n. 2, p. 193-198, 2005. https://doi.org/10.4025/actasciagron.v27i2.1480

BLANKINSHIP, J.C., FONTE, S.J., SIX, J., SCHIMEL, J.P. Plant versus microbial controls on soil aggregate stability in a seasonally dry ecosystem. Geoderma, v. 272, n. 2, p. 39-50, 2016. https://doi.org/10.1016/j.geoderma.2016.03.008

BRONICK, C.J.; LAL, R. Soil structure and management: a review. Geoderma, v. 124, n. 1, p. 3-22, 2005. Acta Scientiarum Agronomy, v. 27, n. 2, p. 193-198, 2005. https://doi.org/10.1016/j.geoderma.2004.03.005

CALONEGO, J. C.; ROSOLEM, C. A. Estabilidade de agregados do solo pós manejo com rotações de culturas e escarificação. Revista Brasileira de Ciência do Solo, v.32, n.4, p. 1399-1407. 2008. https://doi.org/10.1590/S0100-06832008000400004

CAMBARDELLA, C. A; ELLIOT, E. T. Particulate soil organic matters across a grassland cultivation sequence. Soil Science Society of America Journal. v. 5, p. 777-783. 1993. https://doi.org/10.2136 sssaj1992.03615995005600030017x

CASTRO FILHO, C; A LOURENÇO: Aggregate stability under different soil management systems in a red latosol in the state of Parana, Brazil. Soil and Tillage Research. v. 65, p. 45-51, 2002.

CORTEZ, J. W.; ALVES, S.; DA, A. D.; MOURA, M. R. D. de; OLSZEVSKI, N.; NAGAHAMA, J.; DE, $\mathrm{H}$. Physical properties of yellow argisol in the semi arid region of northeastern brazil under tillage systems. Revista Brasileira de Ciência do Solo, v. 35, n. 4, p. 1207-1216. 2011. https://doi.org/10.1590/S0100-06832011000400014.

COSTA, F. de S.; BAYER, C.; ZANATTA, J. A.; MIELNICZUK, J. Carbon stock and carbon dioxide emissions as affected by soil management systems in Southern Brazil. Revista Brasileira de Ciência do Solo, v. 32, n. 1, p. 323-332, 2008.

DADALTO, J. P.; FERNANDES, H. C.; TEIXEIRA, M. M.; CECON, P. R.; MATOS, A. T. de. Sistema de preparo do solo e sua influência na atividade microbiana. Revista Engenharia Agrícola, v.35, n.3, p. 506-513, 2015. http://dx.doi.org/10.1590/1809-4430 
DEBIASI, H.; LEVIEN, R.; TREIN, C. R.; CONTE, O.; KAMIMURA, K. M. Soybean and corn yield after soil winter covers and soil mechanical loosening. Pesquisa Agropecuária Brasileira, v. 45, n. 6, p. 603-612, 2010. https://doi.org/10.1590/S0100-204X2010000600010

DÍAZ-ZORITA, M; PERFECT; J. H. GROVE. Disruptive methods for assessing soil structure: review. Soil and Tillage Research, v. 64, n. 1, p. 3-22, 2002. https://doi.org/10.1016/S0167-1987(01)00254$\underline{9}$

EMBRAPA. Sistema Brasileiro de Classificação de Solos. Embrapa Solos. 3 ed. Brasília, 2013.

FACHIN, P. A.; GONÇALVES JUNIOR, E. V.; THOMAZ, E. L. Comparação entre dois modelos de Agitador de Yoder na avaliação da estabilidade de agregados de solo. Revista Brasileira de Geografia Física v.12, n. 2, p. 697-704. 2019. https://doi.org/10.26848/rbgf.v12.2.p697-704

KEMPER, W.D.; CHEPIL, W.S. Size distribution of aggregates. In: BLACK, C.A.; EVANS, D.D.; WHITE, J.L.; ENSMINGE, L.E.; CLARK, F.E., eds. Methods of soil analysis. Madison, American Society of Agronomy, p. 499-510. 1965.

HILLEL, D. Introduction to environmental soil physics. Amsterdam: Elsevier Academic Press, p. 102-112. 2004.

KEMPER, W. D.; R.C.ROSENAU. Aggregate stability and size distribution. In: KLUTE, A. (ed.). Methods of soil analysis (part 1). Physical and mineralogical methods. Madison, Wisconsin USA: SSSA Book Series n.5. p. 1188. 1986.

KOCHHANN. R.A.; DENARDIN, J.E.; BERTON, A.L. Compactação e descompactação de solos. Passo Fundo, Embrapa Trigo, (Embrapa Trigo. Documentos, 19). 2000.

LEPSCH, I. F. Formação e conservação dos solos. - $2^{\underline{a}}$ ed. São Paulo: Oficina de textos,2010.

MOREIRA, A.; MALAVOLTA, E. Dinâmica da matéria orgânica e da biomassa microbiana em solo submetido a diferentes sistemas de manejo na Amazônia ocidental. Pesquisa Agropecuária Brasileira, v.39, n.11, p.1103-1110, 2004.

MORGAN, R. P. C. Soil erosion and conservation (second edition). Harlow: Longman Group, 2005.

PAUSTIAN, K.;COLLINS, H. P; PAUL, E. A. Management controls on soil carbon. P. 15-49. In: PAUL, E. A, et al. (ed.) Soil organic matter in temperature agroecosystems: Long-term experiments in Noth America. Boca Raton, FL: CRC Press, 1997.

Reyes, J.; Thiers, O.; Gerding, V.; Donoso, P. Effect of scarification on soil change and establishment of and artificial forest regeneration under Nothofagus spp. In Southern Chile. Journal of Soil Science and Plant Nutrition, v. 14(1), p. 115-127. 2014.

RIBON, A. A.; CENTURION, J. F.; CENTURION, M. A. P. da C.; FERNANDES, K. L.; HERMÓGENES, V. T. L. Changes in the aggregate stability of latosol and podzolic according to the management between the rows of rubber trees (Hevea brasiliensis). Revista Árvore, v. 38, n. 6, p. 1065-1071. 2014. https://doi.org/10.1590/S0100-67622014000600011

SALES, R. P.; PORTUGAL, A. F.; MOREIRA, J. A. A.; KONDO, M. K.; PEGORARO, R. F.;. Physical quality of a Latosoil under no-tillage and conventional tillage in the semi-arid region. Revista Ciência Agronômica, v. 47, n. 3, p. 429-438. 2016. https://doi.org/10.5935/1806-6690.20160052.

SALTON, J. C.; MIELNICZUK, J.; BAYER, C.; BOENI, M.; CONCEIÇÃO, P. C.; FABRÍCIO, A. C.; MACEDO, M. C. da M.; BROCH, D. L. Agregação e estabilidade de agregados do solo em sistemas agropecuários em Mato Grosso do Sul. Revista Brasileira de Ciência do Solo. v.32, n.1, p. 1121. 2008. https://doi.org/10.1590/S0100-06832008000100002

SARKER, J.R, SINGH, B.P., COWIE, A.L., FANG, Y. Agricultural management practices impacted carbon and nutrient concentrations in soil aggregates, with minimal influence on aggregate stability 
and total carbon and nutrient stocks in contrasting soils. Soil and Tillage Research, v. 178, p. $209-$ 223. 2018. https://doi.org/10.1016/..still.2017.12.019

SEIDEL, E.P., SCHNEIDER, A.P.H., SUSTAKOWSKI, M.C., MATTÉ, L.M. Soybean Yield, Soil Porosity and Soil Penetration Resistance under Mechanical Scarification in No-Tillage System. Journal of Agricultural Science, v. 10, p. 53-66. 2018. https://doi.org/10.5539/jas.v10n4p268

SIX, J.; ELLIOTT, E. T.; PAUSTIAN, K. Aggregate and Soil Organic Matter Dynamics under Conventional and No-Tillage Systems. Soil Science Society of America Journal, 63: 1350-1358. 1999. https://doi.org/10.2136/sssaj1999.6351350x

VIERA, S. Estatística experimental. Atlas. São Paulo, Brasil. 185 p. 1999.

WALKLEY, A., BLACK, I.A. An examination of the degtjareff method for determining soil organic matter, and a proposed modification of the chromic acid titration method. Soil Science. v. 37, p. 2938. 1934.

YODER, R.E. A direct method of aggregate analysis of soils and a study of the physical nature of erosion losses. American Society of Agronomy Journal, v. 28, n. 5, p. 337-351, 1936.

Recebido em: 09/05/2019

Aceito para publicação em: 03/07/2020 